\title{
THE CASAS GRANDES METEORITE.
}

\author{
By Wirt Tassin, \\ Assistant Curator, Division of Mineralogy.
}

\section{HISTORY.}

One hundred and forty miles southwest of Juarez, or El Paso del Norte, in the State of Chihuahua, Mexico, are the ancient Mexican ruins variously known as Casa Grande, Casas Grandes, Montezuma Casas Grandes, and Casas Grandes de Malintzin, relies of a civilization that before the Spanish invasion occupied the country as far north as Santa Fe. In this ruin certain inhabitants of a small Mexican town, near to and which takes its name from the Casas Grandes ruins. discovered a roundish mass of meteoric iron.

The news of the discovery was published by Tarayre, ${ }^{1}$ who reported that Müller, the director of the mint of Chihuahua, during the course of an exploration of the great temple of the Casas Grandes, brought to light a lenticular mass of meteoric iron 50 centimeters in diameter, carefully wrapped in cloths similar to those enshrouding the mummies in the ancient tombs of the same locality. Later, Mr. William M. Pierson, United States vice-consul at El Paso del Norte, gave a more circumstantial account of the find in a letter ${ }^{2}$ to the State Department, from which the following is taken:

A party of these Mexican mountaineers, as a matter of curious speculation, commenced excavating in the old ruins of the Montezuma Casas Grandes, each man drifting into the old ruins at separate and several points. One, Teodoro Alverado, more fortunate than the others, drifted into a large room, in the middle of which there appeared a kind of tomb made of brick. Curiosity led this bold knight of the crowbar to renew his excavations, and when he had reached the middle of this tomb, he there found this curious mass of meteoric iron * * * carefully and curiously wrapped in a kind of coarse linen *** Angerstein, Leroy, and myself have made up the necessary funds to purchase this rare and novel specimen, making it a mutual adventure, and have started a large mercantile wagon, capable of carrying 10,000 pounds, to transport it to this eity. Our intention is to secure it for the admiration of the curious and the lovers of science. We shall have it safely lodged in the consulate within fifteen days from this date.

${ }^{1}$ Archives de la Commission Scientifique du Mexique, Paris, III, 1867, p. 348.

${ }^{2}$ Smithsonian Report, 1873, p. 419. 
The letter here eited was referred by the Assistant Secretary of State to the then Secretary of the Smithsonian Institution, Professor Henry, who took measures to secure the mass as indicated by the following extract from his reply:

It would give us great pleasure to subject a portion of the meteorite in question to an investigation in regard to its gaseous contents; and if the gentlemen who own it will present it to the Institution, we will cheerfully pay the expense of transportation.

Nothing further was heard from the mass until the centennial year, 1876, when the Institution became the possessor by gift of an uncut block of meteoric iron, purporting to be the Casas Grandes mass, exhibited among the Mexican minerals at the exposition.

\section{DESCRIPTION.}

This is a lenticular mass of iron measuring 97 by 74 by 46 centimeters (38 by 29 by 18 inches) and weighing before cutting 1,544.788 kilos (3,407 pounds). The outer surface of the mass is almost entirely covered with broad, shallow pittings, some of which, as shown in the plates, are quite large. This outer surface is more or less oxidized and in no way differs from the so-called "crust surface" of other meteoric irons containing little or no ferrous chloride.

A portion of the mass was cut for exchange and study purposes by means of a slotter. The iron machined readily and was no harder than ordinary mild steel, with about the same toughness as a low-grade nickel steel. The surface left by the tool measured 55 and 38 centimeters in the two longest diameters and was readily worked down with shop files of increasing fineness, and lastly polished with emery flour. The face thus obtained showed a few small scattered nodules and grains of troilite, the largest not over 2 centimeters in diameter and the smaller, and more numerous, not larger than a pin head. No schreibersite, carbonaceous nodules, or stony matter is visible on the polished surface. After exposure to the action of dilute nitric acid, the polished surface develops the beautiful crystalline structure shown in Plate III. Seen by reflected light, the etched surface shows numerous fine lines of a yellowish to tin white color which was found to be schreibersite. The schreibersite is in general lineally arranged and is usually only to be observed by reflected light, though occasionally it is so prominent as to stand in relief, as shown on the face of the cube here figured.

\section{THE CHEMICAL COMPOSITION.}

The turnings made by the "slotter" were cut into small pieces by means of snips and carefully washed in alcohol and ether to remove any grease or dirt that may have been present, and after thorough drying were bottled and sealed to prevent possible oxidation. A weighed amount (7.02 grams) of these washed clippings was dissolved 
in aqua regia and evaporated to dryness on the water bath; concentrated hydrochloric acid was then added and the whole carefully heated until all the ferric oxide was dissolved and again brought to dryness. This operation was repeated until all the nitric acid was expelled. The residue was then dissolved in 15 cubic centimeters of hydrochloric acid, evaporated till the solution was almost sirupy, and then diluted to about 100 cubic centimeters with cold water and filtered, using the "double filter" method of J. Lawrence Smith." This residue was examined and found to consist entirely of carbon. The filtrate and washings from the above were collected and made up to 1,000 cubic centimeters, and all the determinations were made in the same solution. The analysis gave:

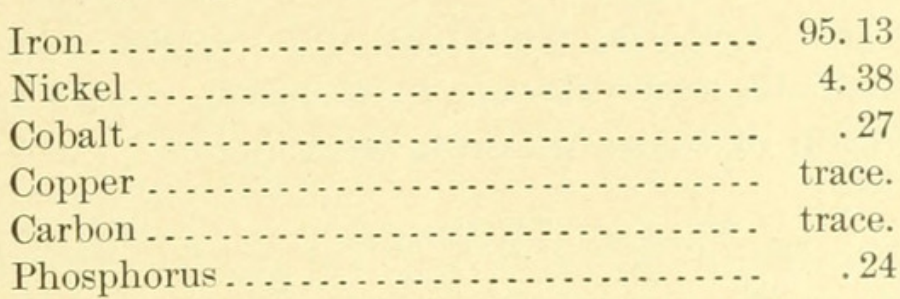

This corresponds to-

Nickeliferous iron .................... 98.65

Schreibersite....................... 1.35

100.00

It will be observed that the analysis shows no sulphur and that the amount of carbon present was practically negligible. While it is evident that the carbon and sulphur contents would naturally vary, it was thought worth while to determine whether or not the nickel-cobalt contents were a constant or not. Accordingly successive samples, weighing as nearly as possible to 5 grams each, were put in solution and made up to a definite amount and portions containing the equivalent of 1 gram of substance taken and the nickel-cobalt contents determined by the acetate method. Each sample was treated as nearly alike as possible and the precipitation being repeated six times with each. It was found that while in certain cases the nickel-cobalt contents did not vary appreciably from the figures given above, in others the variation was considerable, and in one instance the cobalt was wanting entirely. Thus:

\begin{tabular}{|c|c|c|c|}
\hline Constituents. & $a$ & $b$ & $c$ \\
\hline $\begin{array}{l}\text { Nickel.... } \\
\text { Cobalt.... }\end{array}$ & $\begin{array}{r}4.38 \\
.27\end{array}$ & $\begin{array}{r}5.02 \\
.30\end{array}$ & $\begin{array}{r}4.50 \\
.00\end{array}$ \\
\hline
\end{tabular}

These figures show a wide variation in composition in different parts of a mass, the character of whose etch figures is such that it would be 
supposed that the iron was fairly uniform. It is true that the mass itself is large, yet these samples were taken from portions whose distances from each other were so small that they could not be over 30 centimeters apart.

The conclusion seems to be obvious that a bulk analysis is of little value unless made on the entire mass, or upon a very large sample, conditions which in either case are practically impossible to comply with. Second, that mineralogical separations of as large amounts as possible, together with the study of sections, are the safest guide to the composition of a meteoric mass.

\section{THE MINERALOGICAL COMPOSITION.}

In order to arrive at the chemical and physical char cters of the mineral constituents, as troilite, schreibersite, ete., separations looking to the isolation of these minerals were made.

\section{TROILITE.}

A nodule of troilite weighing 1.529 grams was carefully picked from the mass. This had a specific gravity of 4.789 , a brass yellow to bronze color, hardness about that of fluorite ( 4 in the scale), slightly magnetic, and gave on analysis:

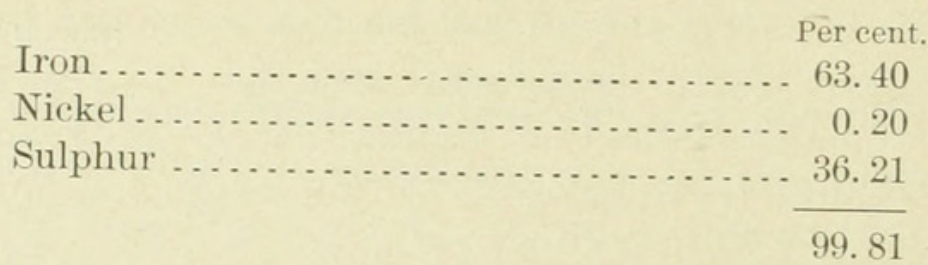

The mineral occurs somewhat sparingly through the mass, usually in nodules varying considerably in size and shape, the one ranging from 1 or 2 centimeters to a millimeter, the other from nearly spherical to lenticular masses, and occasionally filling veins, as shown in the plate. So far as observed the segregation of the sulphide is usually accompanied by the segregation of graphite, commonly as a very thin layer between the troilite and the iron ground mass. In no instance was there noticed a segregation of the phosphide immediately adjacent to the troilite, similar to conditions which may be observed in certain sections of the Canyon Diablo and other irons.

\section{SCHREIBERSITE.}

Successive portions of the iron, amounting in all to $150 \mathrm{grams}$, were treated with a large excess of hydrochloric acid $(1 \mathrm{HCl}, \mathrm{sp} . \mathrm{g} .1 .1+15$ $\mathrm{H}_{2} \mathrm{O}$ ). The several solutions were filtered, and the residues collected and dried. The phosphide was then separated by a magnet, and 1.21 grams of small, brilliant steel-gray folia were thus collected. These were, without further examination, treated with nitric acid for analysis. It was noticed that while a portion of the material went 
almost immediately into solution, the remainder was exseedingly refractory. The refractory material was washed free from acid, dried, and examined under the lens. It was found that the grains were all coated with a colorless, transparent silicate. This was saved and other portions of the iron, amounting in all to $500 \mathrm{grams}$, were treated with dilute hydrochloric acid to secure more phosphide, and, if possible, more of the siliceous mineral for identification.

The phosphide thus secured when examined under the glass showed no evidences of crystalline form, and consisted entirely of small folia and grains, strongly magnetic, and very brittle, having a specific gravity of 7.123 at $20^{\circ}$ C., and gave on analysis:

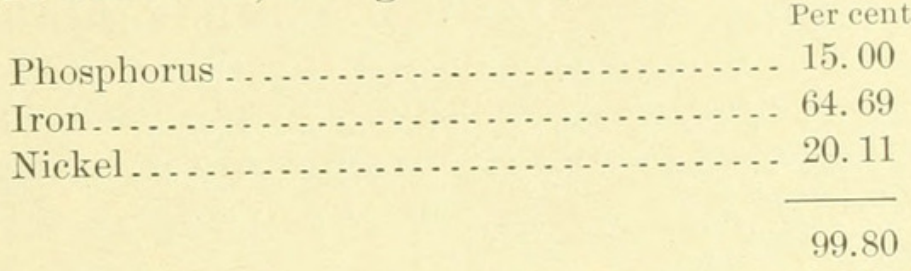

The schreibersite occurs fairly evenly distributed over the mass in fine, hair-like lines and thin plates. It frequently parallels the taenite lamellæ, and not uncommonly occurs as minute blebs and filaments on, and probably grading into, the taenite. The more common occurrence is as fine, hair-like lines and thin plates occurring in the nickelpoor iron and between the nickel-poor and nickel-rich iron. The arrangement agrees with the general structure of the iron, and is so similar to the taenite bands that it may readily be mistaken for them. No nodules of schreibersite are known to occur, and only occasionally are the bands sufficiently distinct to show in a photograph of an etched surface as they do in the print of the cube. (Plate IV.)

\section{TAENITE.}

With considerable difficulty $1.56 \mathrm{grams}$ of thin taenite lamellæ were collected and submitted to an analysis, with the following results:

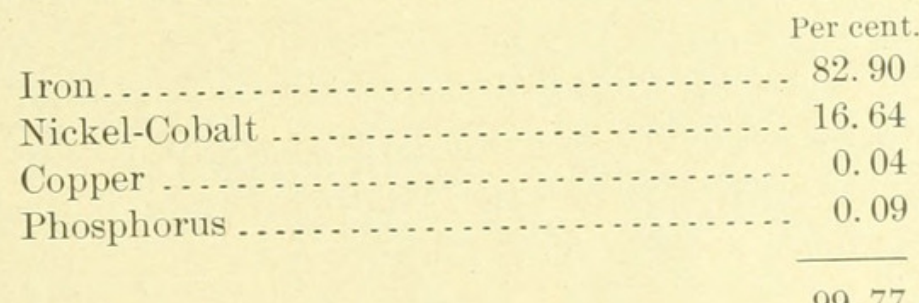

99. 77

This gives the following ratio for $\mathrm{Fe}$ and $(\mathrm{NiCo})$ :

$$
\mathrm{Fe}:(\mathrm{Ni}, \mathrm{Co})=14.80: 2.82=7: 1=\mathrm{Fe}_{2}(\mathrm{Ni}, \mathrm{Co}) \text {. }
$$

The accepted formula for taenite being $\mathrm{Fe}_{6} \mathrm{Ni}$.

\section{CARBON.}

All the carbonaceous residues were collected and examined under the glass for cliftonite without success. The carbon was found to be 
entirely in the graphitic condition. After weighing it was burned in a current of oxygen.

\section{SILICATES AND OTHER MINERALS.}

The only siliceous mineral observed was found coating a small portion of some schreibersite, and though large amounts of iron were treated for the purpose of securing more, none was found. The mineral was clear, colorless, and entirely without effect on polarized light, and not enough of it could be secured for analysis. No other minerals, such as rhabdite, cohenite, chromite, diamond, etc., were observed. 


\section{$2 \mathrm{BHL}$ Biodiversity Heritage Library}

Tassin, Wirt. 1902. "The Casas Grandes meteorite." Proceedings of the United States National Museum 25(1277), 69-74. https://doi.org/10.5479/si.00963801.25-1277.69.

View This Item Online: https://www.biodiversitylibrary.org/item/32399

DOI: https://doi.org/10.5479/si.00963801.25-1277.69

Permalink: https://www.biodiversitylibrary.org/partpdf/9148

\section{Holding Institution}

Smithsonian Libraries

\section{Sponsored by}

Smithsonian

\section{Copyright \& Reuse}

Copyright Status: NOT_IN_COPYRIGHT

This document was created from content at the Biodiversity Heritage Library, the world's largest open access digital library for biodiversity literature and archives. Visit BHL at https://www.biodiversitylibrary.org. 